\title{
DJ-1-induced phosphatase and tensin homologue downregulation is associated with proliferative and invasive activity of laryngeal cancer cells
}

\author{
XIAO-LIN ZHU ${ }^{1,2^{*}}$, WEI SUN ${ }^{1,2^{*}}$, WEN-BIN LEI ${ }^{1,2}$, HUI-WEN ZHUANG $^{1,2}$, \\ WEI-JIAN HOU ${ }^{1,2}$ and WEI-PING WEN ${ }^{1,2}$ \\ ${ }^{1}$ Department of Otorhinolaryngology, Head and Neck Surgery, The First Affiliated Hospital of Sun Yat-Sen University; \\ ${ }^{2}$ Institute of Otorhinolaryngology, Sun Yat-Sen University, Guangzhou, Guangdong 510080, P.R. China
}

Received June 26, 2014; Accepted March 12, 2015

DOI: $10.3892 / \mathrm{mmr} .2015 .3617$

\begin{abstract}
DJ-1, a novel mitogen-dependent oncogene, has an important role in the progression of human malignancies, whereas tumor suppressor phosphatase and tensin homolog (PTEN) is known to control a variety of processes associated with cell survival, proliferation and invasion. DJ-1 overexpression was reported to be negatively correlated with PTEN expression in tumor tissues of patients with laryngeal squamous cell carcinoma (LSCC). In the present study, the effect of DJ-1 on PTEN in laryngeal cancer cells was investigated by transfecting DJ-1-specific small interfering (si)RNA into Hep-2 and SNU-899 cells. Cell survival and cell proliferative and invasive capacity were then evaluated. The results showed that siRNA targeting of DJ-1 effectively upregulated PTEN expression, resulting in enhanced cell death as well as decreased proliferation and invasion of Hep-2 and SNU-899 cells. The results of the present study indicated, for the first time, to the best of our knowledge, that DJ-1-induced PTEN downregulation is associated with proliferative and invasive activity of laryngeal cancer cells. The DJ-1 gene may have an important role in the tumorigenesis of LSCC.
\end{abstract}

\section{Introduction}

Laryngeal squamous cell carcinoma (LSCC), one of the most common malignancies of the head and neck region, accounts for

Correspondence to: Professor Wei-Ping Wen, Department of Otorhinolaryngology, Head and Neck Surgery, The First Affiliated Hospital of Sun Yat-Sen University, 58 2nd Zhongshan Road, Guangzhou, Guangdong 510080, P.R. China

E-mail: wenwp@mail.sysu.edu.cn

${ }^{*}$ Contributed equally

Key words: DJ-1, phosphatase and tensin homologue, tumorigenesis, laryngeal squamous cell carcinoma
$2.4 \%$ of diagnosed malignancies worldwide every year $(1,2)$. Despite novel treatment modalities (including surgical and adjuvant chemo- or radiotherapy) and their success in terms of overall quality of life, survival rates for this disease have not improved in the past 30 years (1). Regional lymph node and distant metastasis and loco-regional recurrence are the two major reasons of LSCC treatment failure $(1,2)$.

At present, an evaluation of LSCC prognosis is primarily based on the clinical tumor, nodes and metastasis (TNM) staging; however, LSCC patients with the same clinical stage often display considerable variability in survival, suggesting that TNM staging is insufficient for precisely predicting the prognosis of this disease (3). Therefore, the discovery of specific biomarkers is important for appropriate therapy and patient surveillance.

DJ-1, also known as Parkinson disease 7 (PARK7) encoding a conserved protein belonging to the ThiJ/PfpI/DJ-1 superfamily (4), was firstly discovered as an oncogene that was able to transform NIH-3T3 cells in co-operation with Ras (5). DJ-1 is localized in the cytoplasm and nucleus, and can be translocated from the former to the latter in the $\mathrm{S}$ phase of the cell cycle. Studies found that the expression of DJ-1 is elevated in prostate cancer and primary lung cancer compared with that in adjacent non-cancerous tissues $(6,7)$; furthermore, its expression is positively correlated with the probability of recurrence in patients with non-small cell lung carcinoma (8). In a previous study of LSCC (9), DJ-1 was identified as an independent molecular marker for poor prognosis, and was correlated with the pT status and tumor grading; this was further confirmed by another study on LSCC (10). Collectively, the above evidence indicated that the DJ-1 gene, which is associated with progression of human malignant tumors and prognosis, may be a potential anti-cancer target. However, the detailed mechanism of the role of DJ-1 in tumorigenesis of laryngeal cancer cells remains to be elucidated.

A recent study by our group reported that overexpression of DJ-1 in LSCC is negatively correlated with the expression of phosphatase and tensin homolog (PTEN), a dual-specific phosphatase that controls a variety of processes associated with cell survival, proliferation and invasion (11). Other studies 
showed that PTEN was downregulated by DJ-1 in several cancer types, including breast and ovarian cancer $(8,12-14)$. These evidences suggested that DJ-1-induced PTEN downregulation may be involved in LSCC progression and act as an activator of the invasion process in LSCC.

In the present study, it was hypothesized that DJ-1-induced PTEN downregulation may be involved in the proliferation and invasion of LSCC. With increasing knowledge of the molecular mechanisms of endogenous RNA interference in cancer studies, small interfering RNAs (siRNAs) directed against the DJ-1 gene in the laryngeal cancer cell lines Hep-2 and SNU-899 was used in the present study. The aim of the present study was to investigate the underlying mechanisms of the involvement of DJ-1 in the tumorigenesis of LSCC.

\section{Materials and methods}

Cell lines and cell culture. The human laryngeal cancer cell line Hep-2 was a kind gift from Dr. Kai-Tao Feng (passage 5; Cell Bank of Experimental Institute of Sun Yat-sen University Cancer Center, Guangzhou, China). The human laryngeal cancer cell line SNU-899 (Passage 7; Korean Cell Line Bank of Cancer Research Institute, Seoul, Korea) was a kind gift from Prof. Stanley Thian Sze Wong (Department of Surgery, Hong Kong University, Hong Kong, China). Hep-2 and SNU-899 cells were maintained in RPMI 1640 media (Sigma-Aldrich, St. Louis, MO, USA) supplemented with $2 \mathrm{mM}$ L-glutamine and 10\% fetal bovine serum (FBS; HyClone Laboratories, Logan, UT, USA). The cultures were grown for a maximum of 10 passages prior to retrieving fresh cells from frozen stock.

RNA extraction and semi-quantitative reverse-transcription polymerase chain reaction (RT-qPCR). RNA extraction and RT-qPCR were performed as previously described (9). Briefly, total RNA was extracted using TRIzol reagent (Fermentas, Thermo Fisher Scientific, Waltham, MA, USA) according to the manufacturer's instructions. The total RNA $(2 \mu \mathrm{g})$ was reverse transcribed using a RevertAid First Strand cDNA synthesis kit (Fermentas) in a $20-\mu 1$ reaction mixture containing $1 \mathrm{X}$ reverse transcriptase $(\mathrm{RT})$ reaction buffer (Fermentas), $0.5 \mu \mathrm{g}$ oligo (dT) 18 primer and $1 \mu \mathrm{l}$ RevertAid Moloney murine leukemia virus (Fermentas) reverse transcriptase for $60 \mathrm{~min}$ at $42^{\circ} \mathrm{C}$, and then heated for $10 \mathrm{~min}$ at $70^{\circ} \mathrm{C}$. After heat inactivation of the RT at $94^{\circ} \mathrm{C}$ for $5 \mathrm{~min}, 1 \mu \mathrm{l}$ of the $\mathrm{RT}$ reaction mixture and $19 \mu \mathrm{l}$ of the PCR mixture (11 $\mu 10.1 \%$ DEPC, $4 \mu 15 \mathrm{X}$ buffer, $2 \mu 110 \mathrm{mM}$ dNTP, $1 \mu \mathrm{l}$ RiboLock $^{\mathrm{TM}}$ ribonuclease inhibitor (Fermentas), $1 \mu 1200 \mathrm{u} / \mu 1$ RevertAid ${ }^{\mathrm{TM}} \mathrm{M}$-MuLV) were mixed and then amplified by PCR (PTC-200 PCR; Bio-Rad Laboratories, Inc., Hercules, CA, USA). The PCR conditions were as follows: DJ-1, $94^{\circ} \mathrm{C}, 5 \mathrm{~min}$ for denaturation, $94^{\circ} \mathrm{C}$ for $45 \mathrm{sec}, 51^{\circ} \mathrm{C}$ for $45 \mathrm{sec}$ and $72^{\circ} \mathrm{C}$ for $10 \mathrm{~min}$, for 29 cycles then $10 \mathrm{~min}$ for the final extension; PTEN, $94^{\circ} \mathrm{C}, 5 \mathrm{~min}$, $94^{\circ} \mathrm{C}$ for $50 \mathrm{sec} ; 58^{\circ} \mathrm{C}$ for $50 \mathrm{sec}$ and $72^{\circ} \mathrm{C}$ for $1 \mathrm{~min}$, for 32 cycles, then $8 \mathrm{~min}$ for final extension. The RT-qPCR products were then eletrophoresed on $1.5 \%$ agarose gel containing ethidium bromide (Sigma-Aldrich) and gel imaging was performed using GelDoc ${ }^{\mathrm{TM}}$ XR (Bio-Rad Laboratories, Inc.). The image was analyzed using Image-Pro Plus 6.0 software (Media Cybernetics, Inc., Rockville, MD, USA). The following primer sequences were used: DJ-1 sense, 5'-GCCAGCCTTGAAGATGCAAA-3' and antisense, 5'-GGCTTGTAAGAATCAGGCCGT-3'; PTEN sense, 5'-CCGAAAGGTTTTGCTACCATTCT-3' and antisense, 5'-AAAATTATTTCCTTTCTGAGCATTCC-3'; S26 sense, 5'-CCGTGCCTCCAAGATGACAAAG-3' and antisense, 5'-GTTCGGTCCTTGCGGGCTTCAC-3'. S26 served as the positive control, and RT-negative samples served as the negative control.

Western blot analysis. Protein extracts of Hep-2 and SNU-899 cells were prepared as previously described (9). Briefly, the cells were harvested and washed with cold phosphate-buffered saline, and total proteins were extracted using lysis buffer (Tris $50 \mathrm{mM}$ pH 8.0, NaCL 150 mM, Sodium deoxycholate $1 \%$, SDS $0.1 \%$, NP-40 1\%, Phenylmethylsulfonyl fluoride $1 \mathrm{mM}$, Aprotinin $10 \mu \mathrm{g} / \mathrm{ml}^{-1}$, Leupeptin $10 \mu \mathrm{g} / \mathrm{ml}^{-1}$ ). Immunoblotting experiments were performed according to standard procedures. Protein concentration was determined using the Bradford assay (Bio-Rad Laboratories, Inc.). Equal amounts of protein $(50 \mu \mathrm{g})$ were separated by electrophoresis on 8-12\% SDS/polyacrylamide gels, and were then transferred onto Biodyne A Membrane (Pall Life Sciences, Ann Arbor, MI, USA). The membranes were then incubated with DJ-1 goat polyclonal antibody (1:1,000; cat. no. sc-27004; Santa Cruz Biotechnology, Inc., Dallas, TX, USA) and PTEN rabbit monoclonal antibody (1:1,000; cat. no. 9559; Cell Signaling Technology, Danvers, MA, USA) overnight at $4^{\circ} \mathrm{C}$. GAPDH mouse monoclonal antibody (1:4,000; cat. no. sc-365062; Santa Cruz Biotechnology, Inc.) was used as an internal loading control. The secondary antibodies for DJ-1, PTEN and GAPDH were rabbit anti-goat (1:2,000; cat. no. SC-2768; Santa Cruz Biotechnology, Inc.), goat anti rabbit (1:1,000; cat. no. 77671; Sigma-Aldrich) and goat anti-mouse (1:2,000; cat. no. 7076; Cell Signaling Technology), respectively. The integrated optical densities of each band were analyzed using Image-Pro Plus 6.0 software.

RNA silencing. As previously described, cells were transfected with the siRNAs using Lipofectamine ${ }^{\mathrm{TM}} 2000$ (Invitrogen Life Technologies, Carlsbad, CA, USA). Scrambled siRNA and small inhibitor duplex RNAs targeting human DJ-1 were designed using an online siRNA selection program (http://www.dharmacon.com/sidesign/default.aspx) and were chemically synthesized by RiboBio Co., Ltd. (Guangzhou, China). The sequences were as follows: DJ-1-specific siRNA, targeting GATTAAGGTCACCGTTGCA (sense, 5'-GAUUAAGGUCACCGUUGCA-3', and antisense, 3'-CUAAUUCCAGUGGCAACGU-5'); and scrambled siRNA targeting TTCTCCGAACGTGTCACGT (sense, 5'-UUCUCCGAACGUGUCACGU-3' and antisense, 3'-AAGAGGCUUGCACAGUGCA-5'), which was used as a scrambled control (9).

MTT assay. Hep-2 and SNU-899 cells were seeded in a 96-well plate at a concentration of $1 \times 10^{4}$ cells/well for $24 \mathrm{~h}$ and transfected with DJ-1-specific siRNA or negative control siRNA by Lipofectamine ${ }^{\mathrm{TM}} 2000$ (Invitrogen Life Technologies). Cell proliferation was assessed at $72 \mathrm{~h}$ after transfection using an MTT assay, as reported previously $(9,15)$. Briefly, $15 \mu 1 \mathrm{MTT}$ 

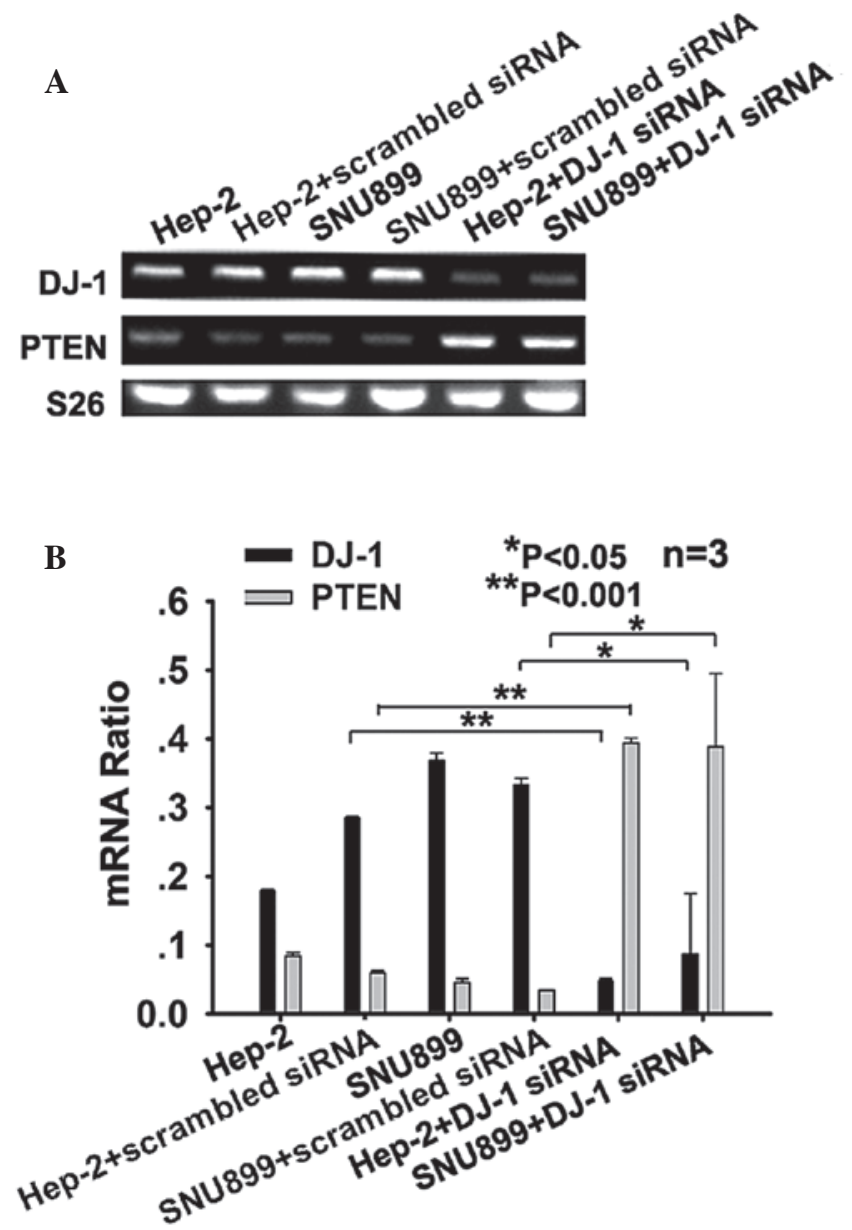

Figure 1. Effect of DJ-1 siRNA on mRNA expression of DJ-1 and PTEN in Hep-2 and SNU-899 cells. (A) mRNA levels of PTEN in Hep-2 and SNU-899 cells transfected with DJ-1 siRNA was determined by semi-quantitative reverse transcription polymerase chain reaction. (B) Densitometric analysis revealed that DJ-1 silencing significantly increased the expression of PTEN compared with that of controls $(\mathrm{P}<0.05 ; \mathrm{P}<0.001)$. Values are expressed as the mean \pm standard deviation $(n=3)$ PTEN, phosphatase and tensin homolog; siRNA, small interfering RNA.

(5 mg/ml; Sigma-Aldrich) was added to each well and incubated at $37^{\circ} \mathrm{C}$ for $4 \mathrm{hr}$, then $150 \mu \mathrm{l}$ dimethly sulfoxide (Sigma-Aldrich) was added to each well. The absorbance (A) value was evaluated using an enzyme linked immunosorbent assay reader (Model 680; Bio-Rad Laboratoties, Inc.). All experiments were repeated three times, and the mean and standard deviation were calculated.

Cell viability assay. At $48 \mathrm{~h}$ post-transfection, the cells were fixed with fixation buffer (eBioscience, San Diego, CA, USA) for $1 \mathrm{~h}$ at room temperature, and stained with X-gal (Sigma-Aldrich) at $37^{\circ} \mathrm{C}$ overnight. Finally, surviving blue cells were counted in five fields using a microscope (ECLIPSE Ti-E; Nikon Corporation, Tokyo, Japan).

Transwell migration assay. The assay was performed as previously described by using chambers with an 8 micron pore size polyethylene terephthalate membrane and a thin layer of matrigel basement membrane matrix $\left(\mathrm{BD}\right.$ BioCoat $^{\mathrm{TM}}$ Matrigel $^{\mathrm{TM}}$ Invasion Chamber; BD Biosciences, San Jose, CA, USA) (16). Forty-eight hours after transfection with
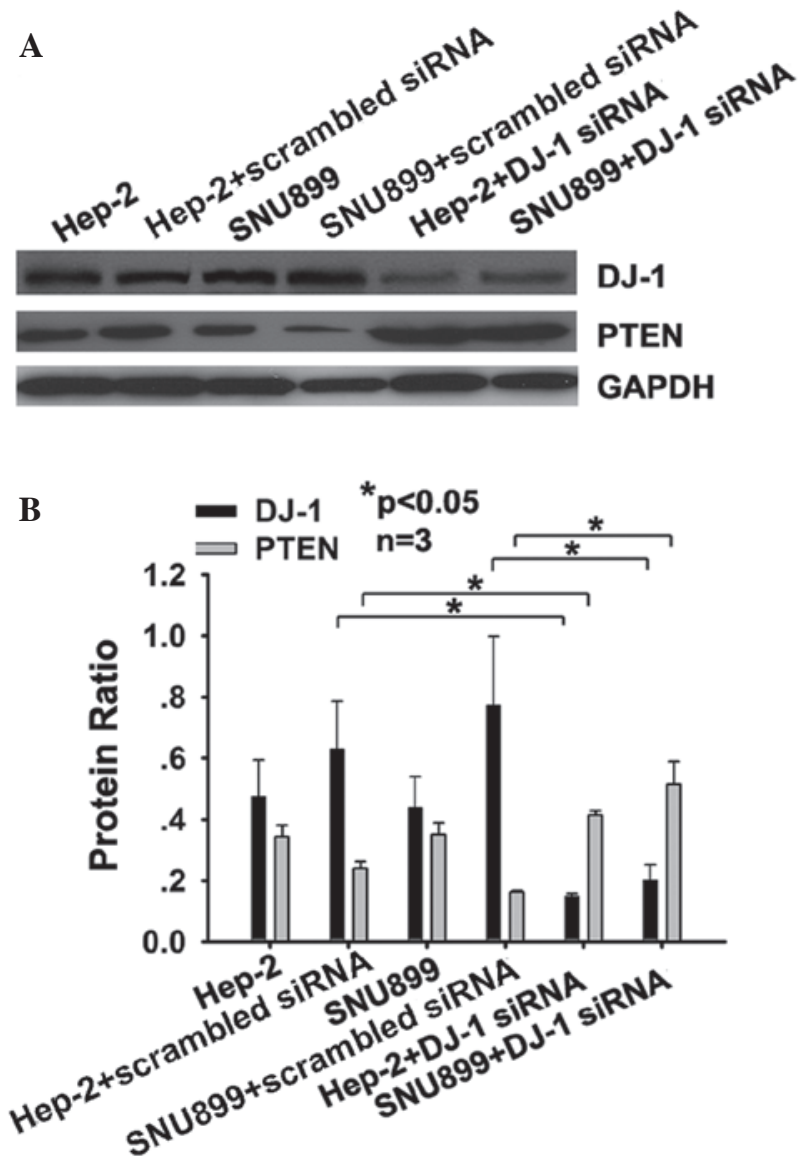

Figure 2. Effect of DJ-1 siRNA on protein expression of DJ-1 and PTEN in Hep-2 and SNU-899 cells. (A) Protein levels of PTEN in Hep-2 and SNU-899 cells transfected with DJ-1 siRNA was determined by western blot analysis. (B) Densitometric analysis revealed that DJ-1 silencing significantly increased the expression of PTEN compared with that of controls $(\mathrm{P}<0.05)$. Values are expressed as the mean \pm standard deviation. PTEN, phosphatase and tensin homolog; siRNA, small interfering RNA.

DJ-1 siRNA, cells and culture medium were harvested, and $2.5 \times 10^{4}$ cells in $0.5 \mathrm{ml}$ harvest medium were placed in the upper chamber. The scrambled siRNA-transfected cells were used as a negative control. The lower chamber was filled with $10 \%$ FBS medium $(0.75 \mathrm{ml})$. After incubation of the cells for $22 \mathrm{~h}$, the cells in the upper chamber were removed with a cotton swab. The cells on the lower side of the filter were permeabilized with fixation/permeabilization buffer (eBioscience) for $1 \mathrm{~h}$ at room temperature, and stained with eosin (Sigma-Aldrich). Finally, the stained cells were counted in five fields using a microscope (ECLIPSE Ti-E; Nikon Corporation).

Statistical analysis. Statistical analysis was performed using SPSS 13 software (SPSS, Inc., Chicago, IL, USA). Student's $t$-test was used for evaluation of differences of gene expression between controls and experiments in vitro. $\mathrm{P}<0.05$ was considered to indicate a statistically significant difference.

\section{Results}

DJ-1 decreases the expression of PTEN at the mRNA level in Hep-2 and SNU-899 cells. To investigate whether DJ-1 regulates the mRNA expression levels of PTEN, Hep-2 and SNU-899 cells 
A

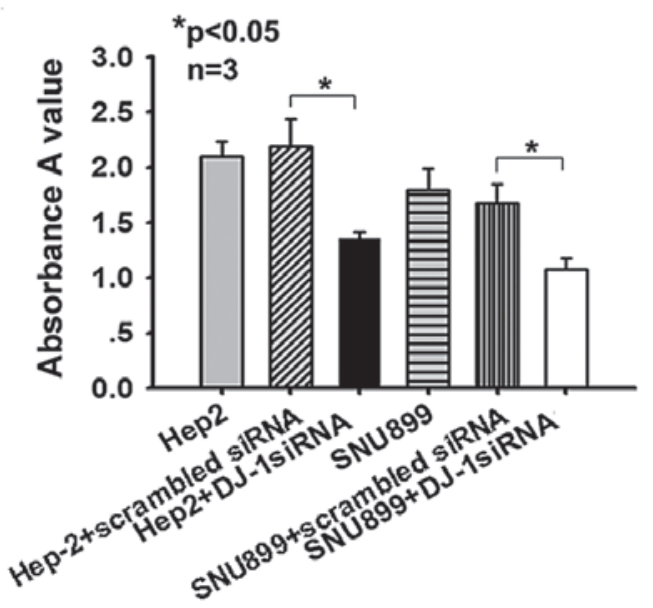

B

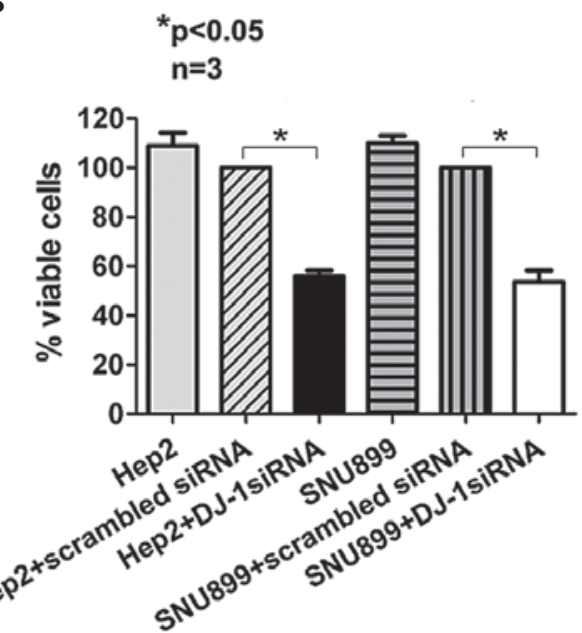

Figure 3. Effect of DJ-1 siRNA on the proliferation and viability of Hep-2 and SNU-899 cells. (A) Hep-2 and SNU-899 cells were transfected with siRNA against DJ-1 $(50 \mathrm{nM})$ using Lipofectamine ${ }^{\mathrm{TM}} 2000$. At $72 \mathrm{~h}$ after transfection, cell viability was assessed using the MTT assay, and the absorbance A value of cells was measured. (B) At $48 \mathrm{~h}$ post-transfection, cells were fixed and stained with X-gal, and surviving blue cells were counted. Data are expressed as \% viability relative to the control transfection, which was lower in the DJ-1 siRNA group compared with that in the control group $(\mathrm{P}<0.05)$. Values are expressed as the mean \pm standard deviation $(n=3)$. siRNA, small interfering RNA.

A

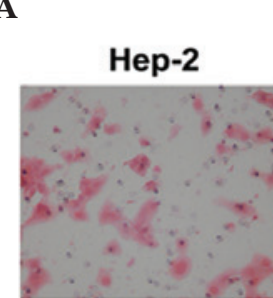

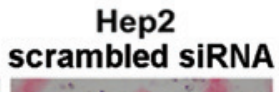

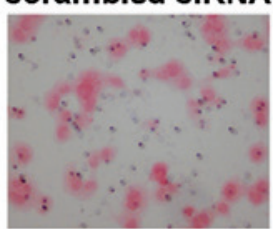

SNU899

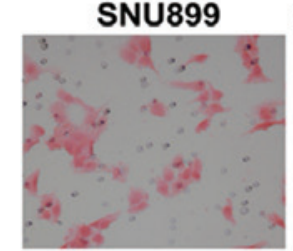

scrambled siRNA

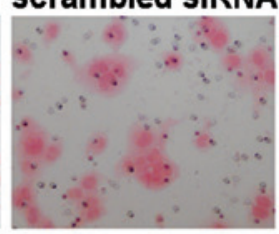

Hep2
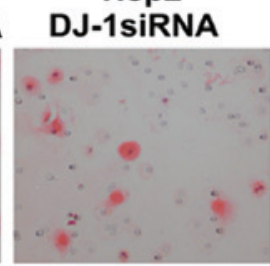

SNU899 DJ-1siRNA

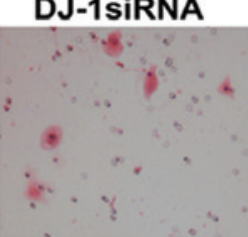

B

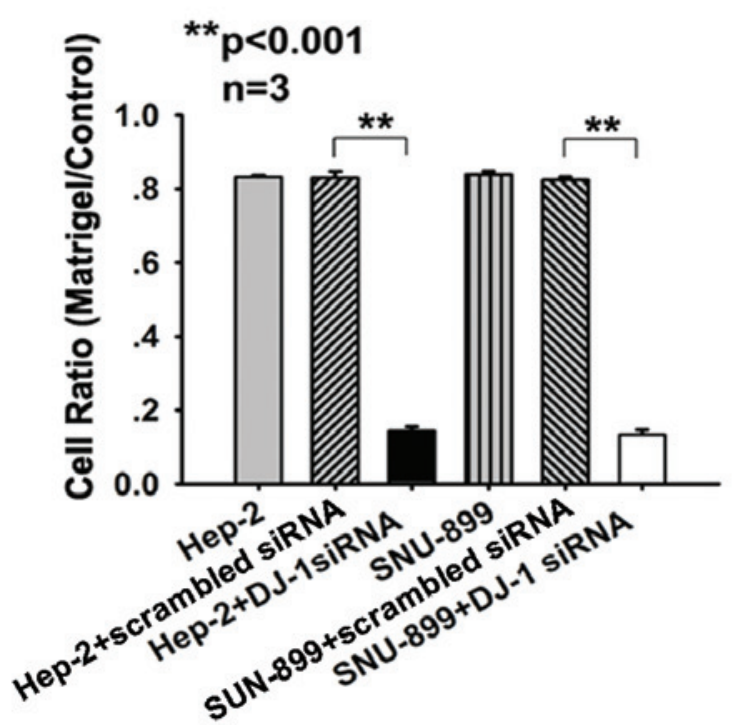

Figure 4. In vitro tumor cell invasive capability assay of DJ-1 siRNA-transfected cells. (A) Representative photos showing the cell density on the filter in Hep-2 and SNU-899 cells transfected with DJ-1 siRNA (eosin staining; x400 magnification). (B) Quantitative analyses of the cells which transgressed through the filter membrane $(\mathrm{P}<0.001)$. Values are expressed as the mean \pm standard deviation $(\mathrm{n}=3)$. siRNA, small interfering RNA.

were then transfected with DJ-1 siRNA or scrambled siRNA and then collected to examine mRNA levels by RT-qPCR. The results showed that DJ-1 silencing significantly increased the mRNA expression levels of PTEN in Hep-2 (P<0.001) and SNU-899 cells $(\mathrm{P}<0.05)$ compared with those in the controls two days following transfection (Fig. 1A and B).

DJ-1 decreases the expression of PTEN at the protein level in Hep-2 and SNU-899 cells. To determine whether DJ-1 has an influence on the levels of PTEN protein, DJ-1 siRNA-transfected cells were assessed for PTEN using western blot analysis. The results showed that three days after DJ-1 siRNA transfection, the levels of PTEN protein in Hep-2 $(\mathrm{P}<0.05)$ and SNU-899 cells $(\mathrm{P}<0.05)$ increased compared with those in cells transfected with scrambled siRNA (Fig. 2A and B). Transfection with the DJ-1 siRNA also affected the protein expression levels of DJ-1 and PTEN, due to the alterations in the mRNA expression levels of the two genes.

Downregulation of DJ-1 decreases proliferation and viability of Hep-2 and SNU-899 cells. Hep-2 and SNU-899 cells were transfected with DJ-1 siRNA for $72 \mathrm{~h}$ and their proliferation was assessed using an MTT assay. The results showed that cell proliferation in the siRNA group was inhibited (Hep-2 cells, $1.35 \pm 0.07$ vs. $2.19 \pm 0.25, \mathrm{P}<0.05$; SNU- 899 cells, $1.08 \pm 0.10$ vs. $1.68 \pm 0.17, \mathrm{P}<0.05$ ) (Fig. 3A). Furthermore, at $48 \mathrm{~h}$ post-transfection, cells were fixed and stained with X-gal, and surviving blue cells were counted. Cell viability in the siRNA group was 
lower than that in the scrambled siRNA-transfected group

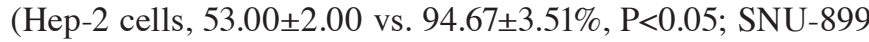
cells, $51.33 \pm 2.52$ vs. $95.67 \pm 3.21 \%, \mathrm{P}<0.05)$ (Fig. 3B).

DJ-1 increases the invasiveness of Hep-2 and SNU-899 cells. As DJ-1 has a negative regulatory function in the invasion in solid cancers $(17,18)$, the present study investigated the migratory activity of DJ-1 siRNA-transfected cells using a Transwell assay. After $22 \mathrm{~h}$ incubation in Matrigel ${ }^{\mathrm{TM}}$ Invasion Chambers, significantly fewer cells migrated through the filter after transfection with DJ-1 siRNA as indicated by reduced migration rates (Hep-2 cells, 0.143 \pm 0.012 ; SNU-899 cells, 0.135 \pm 0.012 ) compared with the migration rate of cells transfected with scrambled siRNA (Hep-2 cells, 0.830 \pm 0.018 ; SNU-899 cells, $0.824 \pm 0.008 ; \mathrm{P}<0.001$ ) (Fig. $4 \mathrm{~A}$ and $\mathrm{B}$ ). These results demonstrated a potential association between the increased PTEN levels and the low invasive capability of Hep-2 and SNU-899 cells. These findings indicated that DJ-1 may be involved in the process of tumor cell invasion via downregulation of PTEN in vitro.

\section{Discussion}

Previous studies showed that DJ-1 has an important role in the development of human malignancies $(7,8)$. Le Naour et al (19) showed that DJ-1 protein levels were increased in the serum of patients with breast cancer and suggested that this protein can be used as a prognostic marker. Subsequent studies reported that DJ-1 overexpression is correlated with poor prognosis of patients with cancer types including pancreatic and esophageal cancers $(20,21)$. In a previous study by our group, DJ-1 expression in tumor tissues was firstly identified as a prognostic marker for patients with laryngeal carcinoma (9), which was further confirmed by another study on laryngeal carcinoma (10). Based on the clinical significance of DJ-1 in human malignancies, its role in tumor progression was assessed in numerous studies. Firstly, DJ-1 protein promoted the proliferation and decreased apoptosis of tumor cells $(6,8,22)$. For instance, Hod (6) showed that DJ-1 protein was able to regulate apoptosis of prostate cancer cells. Kim et al (8) found that DJ-1 protein was able to promote the proliferation of breast cancer cells. Secondly, DJ-1 was associated with aggressive behavior of tumor cells. He et al (17) showed that DJ-1 promoted the invasion and metastasis of pancreatic cancer cells by activating SRC/ERK/uPA signaling. Bai et al (18) found that DJ-1 contributed to the metastasis of non-small cell lung cancer. Moreover, a recent study by our group showed that overexpression of DJ-1 was linked to lymph node metastasis in LSCC patients (11).

In the present study, siRNA directed against the DJ-1 gene was transfected into the laryngeal carcinoma cell line Hep-2 and SNU899 cells, respectively. MTT analysis showed that the proliferation of these cells was significantly inhibited by transfection with DJ-1-siRNA. Furthermore, a cell viability assay showed that transfection with DJ-1-siRNA resulted in decreased cell viability. Finally, the effect of DJ-1 on the invasive activity of laryngeal cancer cells was evaluated using a Transwell migration assay. The results showed that the invasive activity of tumor cells was significantly inhibited following transfection with DJ-1-siRNA.
Several studies showed that DJ-1-induced PTEN downregulation is associated with tumorigenesis of several cancer types $(8,12-14)$. For example, DJ-1 was able to activate cell proliferation by negatively regulating PTEN expression in breast cancer cells (8). Moreover, overexpression of DJ-1 and loss of PTEN are associated with invasive urothelial carcinoma of the urinary bladder (13). A recent study by our group showed that the inverse association between DJ-1 and PTEN was associated with node metastasis of LSCC patients (11). All of the above results indicated that DJ-1 promotes proliferation and invasiveness of laryngeal cancer cells via downregulating the expression of PTEN.

To identify whether DJ-1 was able to downregulate the expression of PTEN in LSCC, transient transfection with DJ-1 siRNA was performed in Hep-2 and SNU-899 cells, which were then analyzed for PTEN expression. The results showed that the mRNA and protein levels of PTEN were increased following DJ-1 siRNA transfection. MTT analysis, viability assay and Transwell migration assay were used to understand whether DJ-1 had a role in the proliferation and invasion of the cells. As expected, the results showed that the percentage of viable cells in the siRNA group was lower than that in the control group, and cell proliferation in the siRNA group was inhibited. Furthermore, the Transwell migration assay showed that the number of cells migrating through the membrane was significantly decreased after transfection with DJ-1 siRNA compared with that of scrambled siRNA-transfected cells. These results indicated that DJ-1 may have an important role in the proliferation and invasive activity of laryngeal cancer cells via downregulation of PTEN.

In conclusion, the present study indicated, for the first time, to the best of our knowledge, a link between the DJ-1 gene and the PTEN gene, and that DJ-1-induced PTEN downregulation may have an important role in the progression of LSCC. However, there the present study had certin limitations; although PTEN was shown to be regulated by DJ-1 the association between PTEN and cell invasion and proliferation was not examined and will be the subject of future studies. Collectively, the findings of the present study provided important information which may be utilized for future design of individualized therapeutic strategies for LSCC, for example, selection of a more aggressive treatment regimen in patients with tumors exhibiting high DJ-1 expression levels.

\section{Acknowledgements}

The present study was supported by the National Natural Science Foundation of China (grant no. 81271055/H1301).

\section{References}

1. Marioni G, Marchese-Ragona R, Cartei G, Marchese F and Staffieri A: Current opinion in diagnosis and treatment of laryngeal carcinoma. Cancer Treat Rev 32: 504-515, 2006.

2. Forastiere A, Koch W, Trotti A and Sidransky D: Head and neck cancer. N Engl J Med 345: 1890-1900, 2001.

3. Kleinsasser O: Revision of classification of laryngeal cancer; is it long overdue? (Proposals for an improved TN-classification). J Laryngol Otol 106: 197-204, 1992.

4. Yang Y, Gehrke S, Haque ME, et al: Inactivation of Drosophila DJ-1 leads to impairments of oxidative stress response and phosphatidylinoditol 3-kinase/Akt signaling. Proc Natl Acad Sci USA 102: 13670-13675, 2005. 
5. Nagakubo D, Taira T, Kitaura H, Ikeda M, Tamai K, Iguchi-Ariga SM and Ariga H: DJ-1, a novel oncogene which transforms mouse NIH3T3 cells in cooperation with ras. Biochem Biophys Res Commun 231: 509-513, 1997.

6. Hod Y: Differential control of apoptosis by DJ-1 in prostate benign and cancer cells. J Cell Biochem 92: 1221-1233, 2004.

7. MacKeigan JP, Clements CM, Lich JD, Pope RM, Hod Y and Ting JP: Proteomic profiling drug-induced apoptosis in non-small cell lung carcinoma: identification of RS/DJ-1 and RhoGDIalpha. Cancer Res 63: 6928-6934, 2003.

8. Kim RH, Peters M, Jang Y, et al: DJ-1, a novel regulator of the tumor suppressor PTEN. Cancer Cell 7: 263-273, 2005.

9. Zhu XL, Wang ZF, Lei WB, Zhuang HW, Jiang HY and Wen WP: DJ-1: a novel independent prognostic marker for survival in glottic squamous cell carcinoma. Cancer Sci 101: 1320-1325, 2010.

10. Shen Z, Ren Y, Ye D, Guo J, Kang C and Ding H: Significance and relationship between DJ-1 gene and surviving gene expression in laryngeal carcinoma. Eur J Histochem 55: e9, 2011.

11. Zhu XL, Wang ZF, Lei WB, Zhuang HW, Hou WJ, Wen YH and Wen WP: Tumorigenesis role and clinical significance of DJ-1, a negative regulator of PTEN, in supraglottic squamous cell carcinoma. J Exp Clin Cancer Res 31: 94, 2012.

12. Sitaram RT, Cairney CJ, Grabowski P, Keith WN, Hallberg B, Ljungberg B and Roos G: The PTEN regulator DJ-1 is associated with hTERT expression in clear cell renal cell carcinoma. Int J Cancer 125: 783-790, 2009.

13. Lee H, Choi SK and Ro JY: Overexpression of DJ-1 and HSP90a and loss of PTEN associated with invasive urothelial carcinoma of urinary bladder: Possible prognostic markers. Oncol Lett 3: 507-512, 2012.
14. Davidson B, Hadar R, Schlossberg A, et al: Expression and clinical role of DJ-1, a negative regulator of PTEN, in ovarian carcinoma. Hum Pathol 39: 87-95, 2008

15. Weichert H, Blechschmidt I, Schröder S and Ambrosius H: The MTT-assay as a rapid test for cell proliferation and cell killing: application to human peripheral blood lymphocytes (PBL). Allerg Immunol (Leipz) 37: 139-144, 1991.

16. Sun W, Guo MM, Han P, et al: Id-1 and the $\mathrm{p} 65$ subunit of NF- $\kappa \mathrm{B}$ promote migration of nasopharyngeal carcinoma cells and are correlated with poor prognosis. Carcinogenesis 33: 810-817, 2012.

17. He X, Zheng Z, Li J, et al: DJ-1 promotes invasion and metastasis of pancreatic cancer cells by activating SRC/ERK/uPA. Carcinogenesis 33: 555-562, 2012.

18. Bai J, Guo C, Sun W, et al: DJ-1 may contribute to metastasis of non-small cell lung cancer. Mol Biol Rep 39: 2697-2703, 2012.

19. Le Naour F, Misek DE, Krause MC, Deneux L, Giordano TJ, Scholl S and Hanash SM: Proteomics-based identification of RS/DJ-1 as a novel circulating tumor antigen in breast cancer. Clin Cancer Res 7: 3328-3335, 2001.

20. Yuen HF, Chan YP, Law S, Srivastava G, El-Tanani M, Mak TW and Chan KW: DJ-1 could predict worse prognosis in esophageal squamous cell carcinoma. Cancer Epidemiol Biomarkers Prev 17: 3593-3602, 2008

21. He XY, Liu BY, Yao WY, et al: Serum DJ-1 as a diagnostic marker and prognostic factor for pancreatic cancer. J Dig Dis 12: 131-137, 2011

22. Junn E, Taniguchi H, Jeong BS, Zhao X, Ichijo $H$ and Mouradian MM: Interaction of DJ-1 with Daxx inhibits apoptosis signal-regulating kinase 1 activity and cell death. Proc Natl Acad Sci USA 102: 9691-9696, 2005. 